\title{
Optimasi Produksi Barang Menggunakan Logika Fuzzy Metode Mamdani
}

\author{
Vani Maharani Nasution, Graha Prakarsa* \\ Fakultas Teknologi dan Informatika, Sistem Informasi, Universitas Informatika dan Bisnis Indonesia, Bandung, Indonesia \\ Email: ${ }^{1}$ vanimaharaninasution@gmail.com, ${ }^{2, *}$ gprakarsa@gmail.com \\ *) Email Penulis Korespondensi: gprakarsa@gmail.com
}

\begin{abstract}
Abstrak-Keuntungan yang maksimal diperoleh dari penjualan yang maksimal. Penjualan yang maksimal artinya dapat memenuhi permintaan-permintaan yang ada. Apabila jumlah produk yang diproduksi oleh perusahaan kurang dari jumlah permintaan maka perusahaan akan kehilangan peluang untuk mendapatkan keuntungan yang maksimal. Oleh karena itu, Perencanaan jumlah produk dalam suatu perusahaan sangatlah penting agar dapat memenuhi permintaan pasar dengan tepat dan dengan jumlah yang sesuai. Faktor-faktor yang perlu diperhatikan dalam menentukan jumlah produk, antara lain permintaan dan persediaan periode lama. Ketersediaan suatu barang produksi masih sulit dipantau oleh perusahaan, karena sistem yang digunakan masih mengandalkan perhitungan manual dari karyawan perusahaan, untuk membantu pihak perusahaan dalam memprediksi ketersediaan barang produksi secara efektif maka digunakan perhitungan fuzzy logic. Selama ini ketersediaan barang produksi di Salman Collection dilihat dari permintaan customer. Hal ini membuat perusahaan tidak mendapatkan keuntungan yang maksimal karena tidak ada perencanaan jumlah produksi barang. Penelitian ini menggunakan metode dengan pendekatan deskriptif menggunakan teknik fuzzy logic mamdani. Hasil penelitian ini adalah sebuah aplikasi pehitungan produksi barang berdasarkan perhitungan manual secara fuzzy logic mamdani, Aplikasi yang dibangun dapat membantu perusahaan menentukan jumlah produksi yang sesuai dengan permintaan konsumen sehingga permintaan di Salman Collection terpenuhi dan lebih optimal jumlah yang akan diproduksi oleh perusahaan.
\end{abstract}

Kata Kunci: Fuzzy Logic, Mamdani, Optimasi, Aplikasi, Produksi

Abstract-Maximum profit gained from maximum sales. Maximum sales means that they can meet the demands. If the products produced by the company is less than requests then the company will lose the opportunity to get maximum profit. Therefore, planning the Amount products in a company is very important in order to meet the market demand precisely and with the appropriate amount. Factors that need to be considered in determining the amount products, such as the demand and supply of old periods. The availability of production goods is still difficult to monitor by the company, because the system is still relying on manual calculations of the company employees, to assist the company in predicting the availability of production goods Effective then used the fuzzy logic calculations. During this time the availability of production goods in Salman Collection is seen from customer request. This makes the company not get the maximum profit because there is no planning the amount of production of goods. This study uses methods with a descriptive approach using the fuzzy logic Mamdani technique. The results of this research is an application of calculation of goods production based on the fuzzy manual calculations of the "logic Mamdani," Built applications can help the company determine the amount of production in accordance with consumer demand so that The demand at Salman Collection is fulfilled and the more optimal the amount that the company will produce.

Keywords: Fuzzy Logic, Mamdani, Optimization, Application, Production

\section{PENDAHULUAN}

Keuntungan yang maksimal diperoleh dari penjualan yang maksimal. Penjualan yang maksimal artinya dapat memenuhi permintaan-permintaan yang ada. Apabila jumlah produk yang diproduksi oleh perusahaan kurang dari jumlah permintaan maka perusahaan akan kehilangan peluang untuk mendapatkan keuntungan yang maksimal. Sebaliknya, apabila jumlah produk yang diproduksi jauh lebih banyak dari jumlah permintaan maka perusahaan akan mengalami kerugian. Oleh karena itu, Perencanaan jumlah produk dalam suatu perusahaan sangatlah penting agar dapat memenuhi permintaan pasar dengan tepat dan dengan jumlah yang sesuai. Faktor-faktor yang perlu diperhatikan dalam menentukan jumlah produksi adalah permintaan dan persediaan periode lama.

Logika Fuzzy merupakan ilmu yang mempelajari mengenai ketidakpastian. Logika fuzzy dianggap mampu untuk memetakan suatu input kedalam suatu output tanpa mengabaikan faktor-faktor yang ada. Logika fuzzy diyakini dapat sangat fleksibel dan memiliki toleransi terhadap data-data yang ada. Salah satu model aturan fuzzy adalah model yang sering digunakan untuk membangun sistem yang penalarannya menyerupai intuisi atau perasaan manusia. Proses perhitungan cukup kompleks sehingga membutuhkan waktu relatif lama, tetapi model ini memberikan ketelitian yang tinggi.

Dengan adanya masalah tersebut, maka untuk menentukan jumlah produksi dalam memenuhi permintaan konsumen diperlukan suatu alternatif pemecahan masalah tanpa menambah fasilitas yang ada, yaitu dengan mengaplikasikan metode fuzzy. Penerapan metode fuzzy dalam perencanaan jumlah produksi barang, diharapkan perusahaan dapat mengatasi permintaan konsumen dengan optimal.

Salah satu penelitian yang membahas tentang bagaiman estimasi produksi [1]. Logika fuzzy merupakan salah satu komponen pembentuk software computing. Logika fuzzy pertama kali diperkenalkan oleh Prof. Lotfi A. Zadeh pada tahun 1965. Dasar logika fuzzy adalah teori himpunan fuzzy. Pada teori himpunan fuzzy, peranan derajat keanggotaan sebagai penentu keberadaan elemen dalam suatu himpunan sangatlah penting. Nilai keanggotaan atau derajat keanggotaan atau membership function menjadi ciri utama dari penalaran dengan logika fuzzy tersebut [2]. Fuzzy logic banyak digunakan pada berbagai penelitian seperti penelitian sebelumnya yaitu penerapan logika 
fuzzy dalam optimasi produksi barang mengunakan metode mamdani [3]. Penelitian untuk perencanaan mengoptimalkan produksi roti pada nusqo bakery [4]. Menentukan jumlah produksi berdasarkan permintaan dan persediaan dengan logika fuzzy dan metode mamdani [5]. Artikel jurnal penelitian yang berjudul Aplikasi Logika Fuzzy Dalam Mengoptimalkan Produksi Minyak Kelapa Sawit Di Pt. Waru Kaltim Plantation Menggunakan Metode Mamdani, menegaskan dan menyampaikan bahwa Seperti halnya himpunan tegas (crisp set), ada beberapa operasi yang didefinisikan secara khusus untuk mengkombinasikan dan memodifikasi himpunan fuzzy. Nilai keanggotaan sebagai hasil dari 2 himpunan sering dikenal dengan nama fire strength atau $\alpha$-predikat [6]. Proses menyelesaikan suatu masalah tertentu supaya berada pada kondisi yang menguntungkan dari suatu sudut pandang. Masalah yang harus diselesaikan berkaitan erat dengan data-data yang dapat dinyatakan dalam suatu atau beberapa variabel. Pengertian menguntungkan, biasanya berhubungan dengan pencarian nilai minimum atau maksimum, bergantung pada sudut pandang yang digunakan [7]. Perancangan aplikasi fuzzy logic dalam menentukan volume produksi dengan mengunakan metode mamdani [8]. Prediksi jumlah produksi mebel menggunakan fuzzy inference system [9]. Sistem penentuan perhitungan jumlah produksi folding gate [10]. Pada penelitian ini melakukan pembuatan aplikasi prediksi jumlah barang produksi berdasarkan permintaan dan persediaan barang yang ada pada perusahaan dengan menerapkan meode fuzzy logic mamdani. Menggunakan fuzzy logic diharapkan dapat membantu pihak perusahaan untuk mengoptimalkan keuntungan penjualan dari barng yang diproduksi karena dengan perhitunga mamdani mampu menghasil tingkat keakuratan yang tinggi.

\section{METODE PENELITIAN}

Penelitian yang lakukan termasuk ke dalam jenis penelitian deskriptif. Pada penelitian ini, peneliti menguraikan aspek-aspek fenomena atau karakteristik variabel atau objek yang menarik untuk diteliti. Dalam penelitian ini, peneliti menggunakan sampel data untuk perhitungan manual secara fuzzy logic mamdani sebagai bahan rujukan untuk membangun aplikasinya.

Pada tahap awal, peneliti menguraikan aspek-aspek fenomena mengenai variabel yang mempengaruhi produksi suatu barang di Salman Collection. Peneliti memahami faktor-faktor yang mempengaruhi produksi barang adalah berdasarkan permintaan dan persediaanbarang, untuk memahami faktok-faktor tersebut, peneliti melakukan pengumpulan data dengan cara studi pustaka dan wawancara. Pada tahap studi pustaka, peneliti mencari jurnal-jurnal yang terkait mengenai optimasi produksi barang melalui internet sebagai data tambahan dari hasil wawancara. Setelah mendapatkan pengetahuan mengenai produksi barang maka dilakukan formalisasi pengetahuan tersebut ke dalam bentuk formal. Kemudian, dari tahap formalisasi setelah itu memecahkannya ke dalam modul-modul dan melakukan pemrograman. Dan pada tahap akhir, dilakukan pengujian terhadap sistem yang telah dibangun guna menemukan kesalahan dan penyempurnaan terhadap aplikasi tersebut.

Tahapan penelitian yang dilakukan dapat dilihat pada gambar 1 berikut ini:

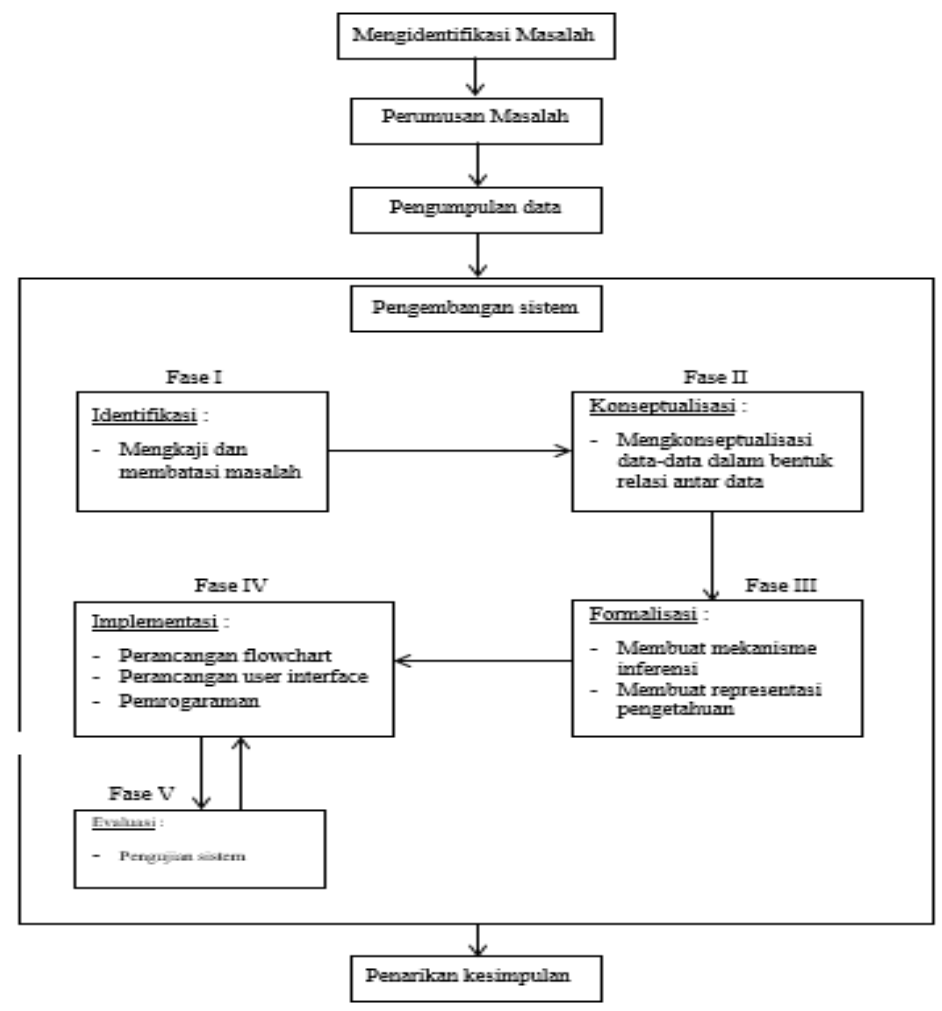

Gambar 1. Tahapan Penelitin 
Pada gambar 1 merupakan tahapan penelitian yang dilakukan selama penelitian, berikut dijelaskan tahapantahapan penelitian:

Mengidentifikasi masalah adalah tahap awal yang dilakukan pada penelitian ini, dimana peneliti melihat masalahmasalah apa saja yang dialami oleh perusahaan untuk memproduksi suatu barang. Pada tahapan ini peneliti menemukan 2 varibel pokok yang sangat mempengaruhi produksi suatu barang yaitu variabel permintaan dan variabel persediaan.

Perumusan masalah merupakan tindak lanjut dari identifikasi masalah dan batasan masalah yang diteliti. Sejumlah pertanyaan-pertanyaan diajukan dalam perumusan masalah, kemudian akan dijawab dalam proses penelitian dan tertuang secara sistematis dalam laporan penelitian. Semua bahasan dalam laporan penelitian, termasuk juga semua bahasan mengenai kerangka teori dan metodologi yang digunakan, semuanya mengacu pada perumusan masalah.

Pengumpulan data merupakan tahapan peting dalam proses penelitian, karena hanya dengan mendapatkan data yang tepat maka proses penelitian akan berlangsung sampai penelitian mendapatkan jawaban dari perumusan masalah yang sudah ditetapkan. Data-data yang digunakan dalam penelitian ini meliputi data primer data sekunder. Data primer didapat dengan cara observasi lansung ke tempat penelitian untuk mengumpulkan semua data yang diperlukan untuk peenelitian sedangkan untuk data seunder dilakukan dengan studi literatur dari beberapa penelitian terdahulu serta referensi buku pendukung untuk pembahasan teori yang dibutuhkan dalam penelitian. Pengembangan sistem adalah tahap pembuatan aplikasi berdasarkan perhitungan data yang telah dikumpulkan pada tahap pengumpulan data. Data yang terkumpul dilakukan pemeriksaan terhadap kemungkinan kesalahan yang terjadi pada data yang diterima. Data yang sudah diperiksa dan berkaitan dengan penelitian diolah menjadi informasi yang akan dijadikan dasar untuk mengembangkan perangkat lunak.

Hal yang dilakukan pada tahapan ini adalah mengumpulkan informasi tentang kebutuhan aplikasi yang akan dibuat. Proses ini mendefinisikan secara rinci mengenai fungsi- fungsi, batasan dan tujuan dari aplikasi dimana akan menguraikan kebutuhan antar muka (interface), kebutuhan informasi dan data-data sebagai masukan (input) kedalam aplikasi sehingga menghasilkan (output) yang sesuai dengan kebutuhan pengguna, kebutuhan fungsional dan pemodelan aplikasi yang akan dibangun (pemodelan menggunakan ERD, DFD dan Kamus Data). Selanjutnaya dilakukan proses perancangan berdasarkan kebutuhan perangkat lunak yang sudah ditemukan. Langkah berikutnya adalah tahapan pembuatan program dengan menggunakan kode-kode program dari desain yang telah dirancang. Setelah pengkodean program selesai maka dilakukan lah proses mengujian terhadap aplikasi yang dibangun.

Pengujian dilakukan dengan mengunakan aplikasi pendukung yang dibuat dengan menggunakan alat bantu Black box testing dengan menguji beberapa komponen diantaranya pengujian fungsi yang hilang atau salah, kesalahan antar muka, kesalahan pada struktur data atau akases basis data eksternal, kesalahan prilaku atau kinerja dankesalahan inisialisasi dan diterminasi.

Tahap akhir adalah penarikan kesimpulan akan dilakukan jika pada proses pengujian tidak terjadi kesalahan yang ditemukan lagi. Isi dari kesimpulan adalah menjawab semua masalah yang telah dirumuskan sebelumnya.

\section{ANALISA DAN PEMBAHASAN}

\subsection{Hasil Penelitian}

Hasil penelitian ini berupa sebuah aplikasi yang mampu menyelesaikan permasalahan yang ada di Salman Collection yaitu menentukan jumlah produksi barang sesuai dengan permintaan konsumen. Aplikasi ini berguna sebagai media penyimpanan data-data dan juga dapat membantu pengguna dalam memprediksi produksi barang sesuai dengan kebutuhan konsumen. Data produksi diperoleh dari data permintaan dan data persediaan dimana didalamnya terdapat banyak data yang telah diinput oleh operator order dan operator gudang, yang nantinya akan diproses oleh Administrator dan menghasilkan prediksi produksi barang.

Permasalahan yang dialami perusahaan diselesaikan menggunakan perhitungan Logika Fuzzy mamdani dimulai dengan pembentukan himpunan fuzzy, aplikasi fungsi implikasi, komposisi aturan, dan defuzzifikasi. Berdasarkan tahapan fuzzy logic mamdani ini maka diperlukan sampel data untuk melakukan perhitungan prediksi jumlah barang yang akan diproduksi. Perhitungan fuzzy logic mamdani menggunakan 2 variabel input yaitu permintaan dan persediaan barang.

Variabel beserta himpunan yang dibutuhkan untuk perhitungan optimasi produksi barang menggunakan sampel data 4 tahun terakhir yang dapat dilihat pada tabel sebagai berikut:

Tabel 1. Permintaan dan Persediaan Tahun 2016-2019

\begin{tabular}{cccc}
\hline Bulan (Tahun) & Permintaan (Kodi) & Persediaan (kodi) & Produksi (kodi) \\
\hline Januari (2019) & 2520 & 250 & 2550 \\
Februari (2019) & 2100 & 174 & 2200 \\
Maret (2019) & 2685 & 233 & 2750 \\
April (2019) & 2740 & 154 & 2800 \\
Mei (2018) & 3070 & 200 & 3050 \\
\hline
\end{tabular}


JURNAL MEDIA INFORMATIKA BUDIDARMA

Volume 4, Nomor 1, Januari 2020, Page 129-135

ISSN 2614-5278 (media cetak), ISSN 2548-8368 (media online)

Available Online at https://ejurnal.stmik-budidarma.ac.id/index.php/mib

DOI 10.30865/mib.v4i1.1719

\begin{tabular}{clll}
\hline Juni (2018) & 2960 & 198 & 3000 \\
Juli (2018) & 2710 & 130 & 2750 \\
Agustus (2017) & 3140 & 100 & 3100 \\
September (2017) & 3120 & 131 & 3100 \\
Oktober (2017) & 2880 & 150 & 2900 \\
November (2016) & 3500 & 115 & 3550 \\
Desember (2016) & 3045 & 131 & 3250 \\
Januari (2016) & 3200 & 140 & 3400 \\
\hline
\end{tabular}

Berdasarkan tabel 1, permintaan terbesar mencapai 3500, dan permintaan terkecil mencapai 2100. Persediaan barang terbanyak 250, dan terkecil mencapai 100. Saat ini Salman Collection hanya mampu memproduksi paling banyak 5000, dan diharapkan dapat memproduksi sedikitnya 1000.

Dalam kasus ini ditentukan 3 variabel penentu untuk membentuk himpunan fuzzy yaitu: variabel input, variabel permintaan dan variabel persediaan, sedangkan output terdapat 1 variabel yaitu produksi barang. Variabel permintaan memiliki 2 variabel linguistik, yaitu naik dan turun, variabel persediaan memiliki 2 variabel linguistik yaitu banyak dan sedikit, sedangkan variabel produksi barang memiliki 2 variabel linguistik yaitu bertambah dan berkurang. Maka aturan-aturan yang dapat terbentuk dapat disajikan dalam tabel 2.

Tabel 2. Pembentukan Aturan-Aturan

\begin{tabular}{ccccc}
\hline Aturan & Permintaan & Persediaan & Fungsi Implikasi & Produksi \\
\hline R1 & Turun & Banyak & $\Rightarrow$ & Berkurang \\
R2 & Turun & Sedikit & $\Rightarrow$ & Berkurang \\
R3 & Naik & Banyak & $\Rightarrow$ & Bertambah \\
R4 & Naik & Sedikit & $\Rightarrow$ & Bertambah \\
\hline
\end{tabular}

Dari table 2, fungsi fuzzyfikasi yang dilakukan dengan menggunakan 3 variabel penentu dengan perhitungan sebagi berikut:

Permintaan (x), terdiri atas 2 himpunan fuzzy, yaitu TURUN dan NAIK. Berdasarkan data permintaan terbesar dan terkecil, maka fungsi keanggotaan memakai rumus representasi linear naik.

$\begin{aligned} \mu \text { PmtTURUN [3200] } & =(3500-\mathrm{x}) / 3500-2100 \\ & =3500-3200 / 3500-2100 \\ & =300 / 1400 \\ & =0,2 \\ & =(\mathrm{x}-2100) / 3500-2100 \\ & =3200-2100 / 3500-2100 \\ & =1100 / 1400 \\ & =0,7\end{aligned}$

Persediaan (y), terdiri atas 2 himpunan fuzzy, yaitu SEDIKIT dan BANYAK. Berdasarkan dari persediaan terbanyak dan terkecil, maka fungsi keanggotaan memakai representasiumus linear naik

$$
\begin{aligned}
\mu \text { PsdSEDIKIT [140] } & =(250-y) /(250-100) \\
& =250-140 / 250-100 \\
& =0,7 \\
\mu \text { PsdBANYAK }[140] & =(y-100) /(250-100) \\
& =140-100 / 250-100 \\
& =0,2
\end{aligned}
$$

Aturan yang digunakan adalan aturan MIN pada fungsi implikasinya:

Rule 1: IF (PermintaanTurun) And (Persediaan Banyak) then (Produksi Berkurang)

$$
\begin{aligned}
\alpha \text {-predikat1 } & =\mu \text { PmtTurun } \cap \mu \text { PsdBanyak } \\
& =\operatorname{Min}(\mu \text { PmtTurun }[3200]),(\mu \text { PsdBanya }[140]) \\
& =\operatorname{Min}(0,2 ; 0,2)
\end{aligned}
$$

$=0,2$

Rule 2: IF (PermintaanTurun) And (Persediaan Sedikit) then (Produksi Berkurang)

$$
\begin{aligned}
\alpha \text {-predikat2 } & =\mu \text { PmtTurun } \cap \mu \text { PsdSEDIKIT } \\
& =\operatorname{Min}(\mu \text { PmtTurun [3200], } \mu \text { PsdSedikit [140]) } \\
& =\operatorname{Min}(0,2 ; 0,7) \\
& =0,2
\end{aligned}
$$

Rule 3: IF (Permintaan Naik) And (Persediaan Banyak) then (Produksi Bertambah)

$$
\begin{aligned}
\alpha-\text { predikat3 } & =\mu \text { PmtNaik } \cap \mu \text { PsdBanyak } \\
& =\operatorname{Min}(\mu \text { PmtNaik [3200], } \mu \text { PsdBanyak [140] }) \\
& =\operatorname{Min}(0,7 ; 0,2) \\
& =0,2
\end{aligned}
$$


Rule 4: IF (Permintaan Naik) And (Persediaan Sedikit) then (Produksi Berkurang)

$\alpha$-predikat4 $\quad=\mu$ PmtNaik $\cap \mu$ PsdSedikit

$=\operatorname{Min}(\mu$ PmtNaik [3200], $\mu$ PsdSedikit [140])

$=\operatorname{Min}(0,7 ; 0,7)$

$=0,7$

Aplikasi fungsi tiap aturan, digunakan metode MAX untuk melakukan komposisi antar semua aturan.

$$
\begin{aligned}
& ((\mathrm{a} 1-1000) / 4000) \quad=0,267 \\
& \text { a1 } \quad=4000(0,267)+1000 \\
& \text { a1 } \quad=2067 \\
& ((\mathrm{a} 2-1000) / 4000 \quad=0,733 \\
& \text { a2 } \quad=4000(0,733)+1000 \\
& \text { a2 }=3933
\end{aligned}
$$

Jadi, dapat disimpulkan bahwa semesta pembicara dengan nilai batas bawah 2067 dan nilai batas atas 3933 . Perancangan merupakan hasil dan tahap lanjutan dari proses analisis sebelumnya atau dengan kata lain perancagan merupakan representasi dari analisis sehingga menghasilkan suatu sistem yang sesuai dengan kebutuhan. Rancangan arsitektur menu merupakan sebuah diagram yang menggambarkan mengenai menu dalam perangkat lunak, struktur menu yang dirancang disesuaikan dengan hak akses dari masing-masing pengguna. Terdapat tiga pengguna dari perangkat lunak aplikasi yaitu administrator, operator order dan operator gudang.

Aplikasi yang telah selesai dirancang diimpelmentasi sesuai dengan perhitungn fuzzy yang telah dilakukan secara manual. Implementasi sistem merupakan proses pembangunan perangkat lunak lanjutan dari kegiatan perancangan. Tujuannya adalah untuk mengkonfirmasi modul program perancangan kepada para pelaku sistem sehingga pengguna dapat memberi masukan kepada pembangun sistem. Perangkat yang diperlukan untuk menjalankan Aplikasi Optimasi Produksi Barang Menggunakan Logika Fuzzy metode Mamdani adalah perangkat lunak sistem operasi yang dapat mendukung penggunaan, Microsoft Visual Studio 2010, web server, database management system (DBMS), serta browser.

\subsection{Implementasi}

Berikut adalah tampilan implementasi antarmuka pada aplikasi optimasi produksi barang. Tampilan muka aplikasi merupakan halaman untuk semua pengguna melakukan autentifikasi pengguna. Pada halaman ini terdapat dua buah text field yaitu username dan password, lalu terdapat satu buah combobox yaitu level yang diperlukan untuk masuk ke dalam aplikasi.

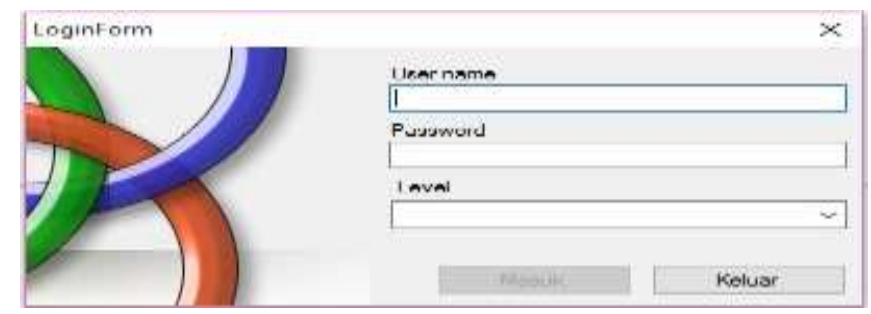

Gambar 2. Halaman Utama

Halaman utama operator order, Pada halaman ini terdapat tiga menu yang terletak dibagian atas yaitu ubah password untuk merubah password operator order, data permintaan untuk menginput data permintaan, dan keluar untuk keluar dari halaman utama.

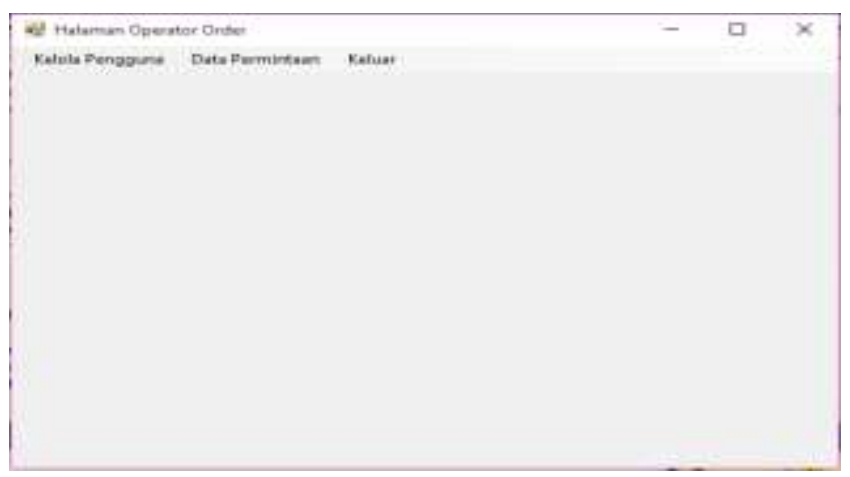

Gambar 3. Gambar Utama Operator Order

Halaman data perminta merupakan halaman untuk operator order menginput data permintaan, terdapat dua text field yaitu id permintaan dan permintaan, dua combo box yaitu tanggal dan jenis barang, dan empat tombol yaitu input/tambah, hapus, ubah dan keluar. 
Available Online at https://ejurnal.stmik-budidarma.ac.id/index.php/mib DOI 10.30865/mib.v4i1.1719

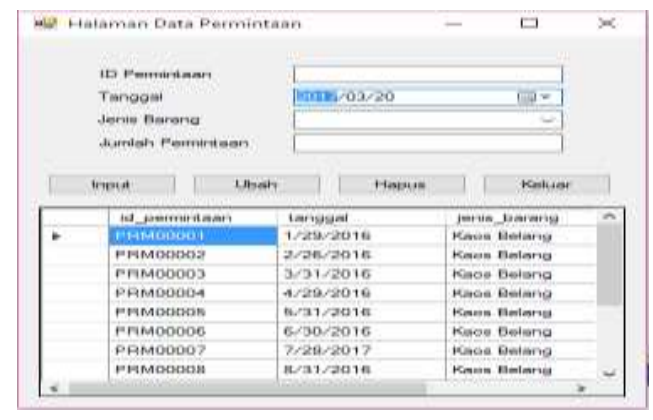

Gambar 4. Data Permintaan

Halaman operator gudang merupakan halaman utama operator gudang. Pada halaman ini terdapat tiga menu yang terletak dibagian atas yaitu ubah password untuk merubah password operator gudang, data persediaan untuk menginput data persediaan, dan keluar untuk keluar dari halaman utama.

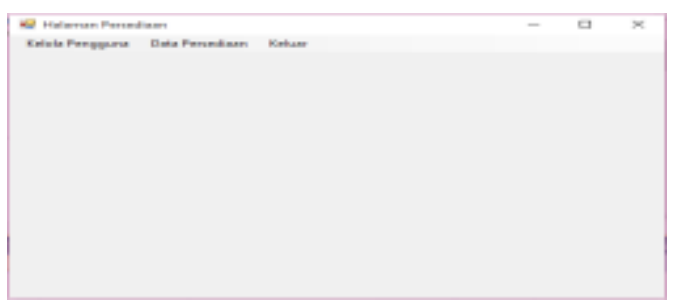

Gambar 5. Operator Gudang

Halaman data persediaan merupakan halaman untuk operator gundang menginput data persediaan, terdapat dua text field yaitu id persediaan dan persediaan, dua combo box yaitu tanggal dan jenis barang, dan empat tombol yaitu input/tambah, hapus, ubah dan keluar

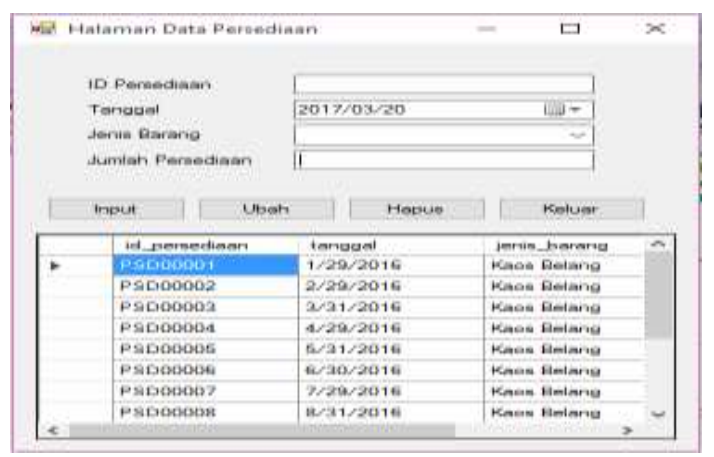

Gambar 6. Data Persediaan

Halaman data produksi administrator akan memproses data yang telah diinput dengan cara memilih tahun dan jenis barang untuk mengetahui nilai maksimum dan minimum dari data permintaan dan persediaan, lalu memilih bulan dan tahun dari data permintaan dan persediaan. Setelah itu administrator tekan tombol pilih agar data yang dibutuhkan muncul di text field data produksi. Setelah data yang akan diproses muncul tekan hitung untuk memperoleh nilai prediksi produksi. Dan setelah selesai administrator bisa menyimpan data hasil prediksi produksi dengan cara menekan tombol simpan.

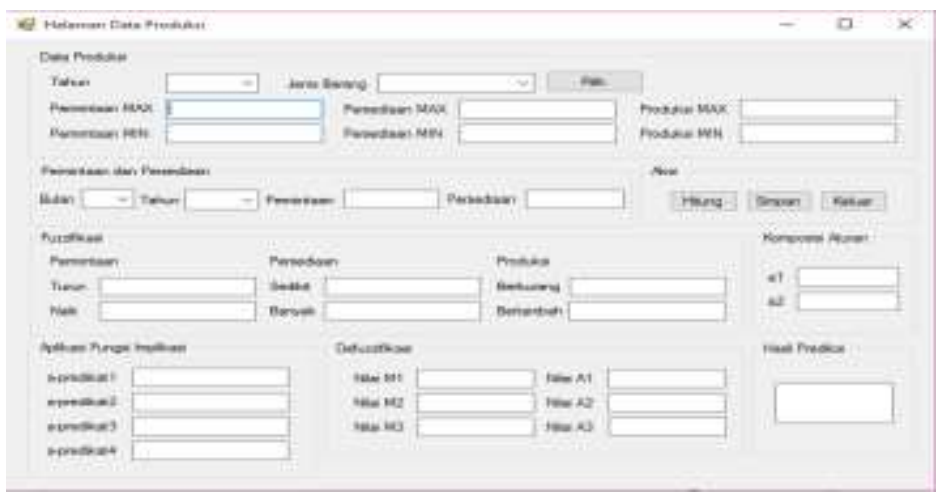

Gambar 7. Data Produksi 
Halaman Laporan administrator bisa melihat data-data yang terkumpul dan juga dapat mencetak data tersebut sebagai laporan. Untuk mencetak laporan, Administrator harus memilih terlebih dahulu tahun yang terletak dicombobox, lalu tekan pilih agar data yang dipilih sesuai dengan yang akan dicetak, langkah terakhir klik tombol print agar data tersebut bisa dicetak.

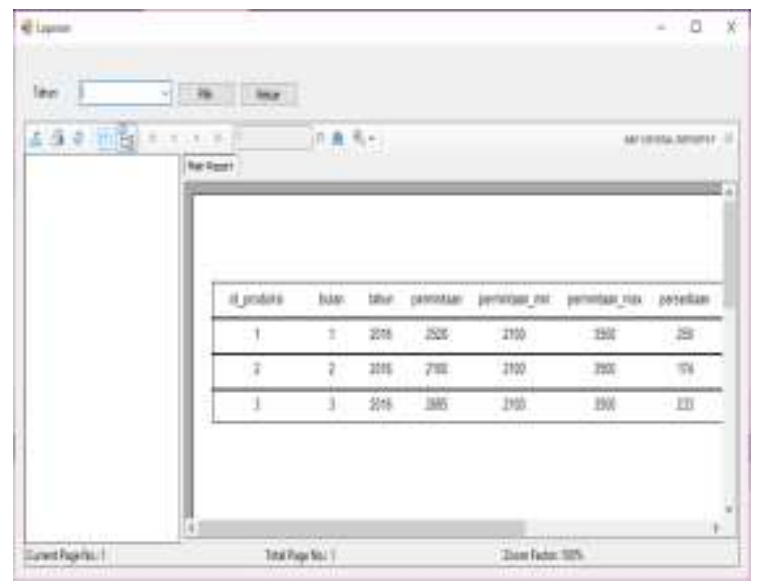

Gambar 8. Data Laporan

\section{KESIMPULAN}

Berdasarkan hasil analisis dan perancangan perangkat lunak aplikasi optimasi produksi barang menggunakan Logika Fuzzy metode mamdani, maka dapat diambil kesimpulan bahwa dengan dibangunnya aplikasi ini dapat membantu perusahaan menentukan jumlah produksi yang sesuai dengan permintaan konsumen dan dengan mengaplikasikan Logika Fuzzy metode Mamdani sebagian besar permintaan di Salman Collection terpenuhi dan lebih optimal dibandingkan dengan sistem lama atau jumlah yang di produksi oleh perusahaan. Perhitungan dengan menggunkan aplikasi ini semakin lebih akurat dan tidak memakan waktu lama dan pihak lebih mudah dalam mengambil keputusan untuk jumlah barang yang akan diproduksi. Selain itu perancangan aplikasi ini mempermudah pihak perusahaan untuk memprediksi 5 tahun produksi barang secara optimal berdasarkan permintaan dari tahun-tahun sebelumnya.

\section{REFERENCES}

[1] Rusli, M., 2017. Dasar Perancangan Kendali Logika Fuzzy. Ke1 ed. Malang: UB Press.

[2] Zainudin, Zukhri. 2014. Metode Komputasi Evolusioner untuk Menyelesaikan Masalah Optimasi. Algoritma Genetika: Yogyakarta: Andi

[3] Wahyu, 2017. Penerapan Logika Fuzzy dalam Optimasi Produksi Barang Menggunakan Metode Mamdani. Soulmath, 5 (01), pp.14-21.

[4] Novi dan Huzain, 2017. Penerapan Logika Fuzzy dalam Optimasi Produksi Barang Menggunakan Metode Mamdani. Soulmath, 5 (01), pp.14-21.

[5] Anitaria dan Marlina, 2017. Menentukan Jumlah Produksi Berdasarkan Permintaan Dan Persediaan Dengan Logika Fuzzy Metode Mamdani. Semnastikaunimed, pp.1-11

[6] Wardani, R. W., Nasution, Y. N. \& Amijaya, F. D. T., 2017. Aplikasi Logika Fuzzy Dalam Mengoptimalkan Produksi Minyak Kelapa Sawit Di Pt. Waru Kaltim Plantation Menggunakan Metode Mamdani. Jurnal Inforamatika Mulawarman, 12 (02), pp. 94-103.

[7] Sri, Kusumadewi, Hari, Purnomo. 2013. Aplikasi Logika Fuzzy untuk Pendukung Keputusan Edisi 2. Yogyakarta: Graha Ilmu.

[8] Sri, 2017. Perancangan Aplikasi Fuzzy Logic dalam Menentukan Volume Produksi dengan Menggunakan Metode Mamadani. Jurnal Teknologi Informasi dan Pendidikan, 10 (01), pp.1-10.

[9] Try dkk, 2018. Prediksi Jumlah Produksi Mebel pada cv. Sinar Sukses Manado Menggunakan Fuzzy Inference System. Decartesian, 7 (1), pp.29-34.

[10] Laily, 2014. Sistem Penentuan Perhitungan Jumlah produksi Folding gate Menggunkan Fuzzy logic. Jurnal Sistem Informasi, 1 (1), pp.12-15 